\title{
Nephrogenic systemic fibrosis (NSF) and gadolinium-based contrast media
}

\author{
P S Ngoya, MD, MSc; Z Vawda, MB BCh; J w Lotz, MA, MSc, FRCR \\ Radiodiagnosis Division, University of Stellenbosch and Tygerberg Academic Hospital, Parow, Western Cape, South Africa.
}

Corresponding author: P S Ngoya (pienems@yahoo.com)

\begin{abstract}
Nephrogenic systemic fibrosis (NSF), unknown before March 1997 and first described in 2000, is a systemic disorder characterised by widespread tissue fibrosis. The first known case occurred in 1997, after the use of gadolinium-based contrast agents (GBCAs) at high doses in patients with renal failure had become routine. An overwhelming majority occurred within weeks to months after injection of a GBCA. The link between nephrogenic systemic fibrosis (NSF) and GBCAs was recognised in 2006. This note comprises guidelines on the prevention of NSF.
\end{abstract}

S Afr J Rad 2013;17(3):106-107. DOI:10.7196/SAJR.935

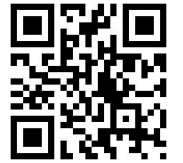

Gadolinium-DTPA (Gd-DTPA), introduced in 1988, is the first paramagnetic contrast agent approved for clinical use in MR imaging. The frequency of adverse reactions is low. Nephrogenic systemic fibrosis (NSF), unknown before March 1997 and first described in 2000 , is a systemic disorder characterised by widespread tissue fibrosis. Originally known as nephrogenic fibrosing dermopathy (NFD) because of its dominant cutaneous findings, the nomenclature was revised in recent years to reflect an increased understanding of its systemic effects. Typical is the unique histopathology of NSF that includes thickened collagen bundles with surrounding clefts, increased dermal mucin deposition, proliferation of dendritic cells and increased elastic fibers. ${ }^{[1]}$

\section{Gadolinium in NSF}

Although gadolinium is a rare-earth metal, with the atomic number 64 on the periodic table, it is in fact widespread in the earth's crust. The first known case of NSF occurred in 1997, after the use of gadolinium-based contrast agents (GBCAs) at high doses in patients with renal failure had become routine. NSF is only observed in patients with severe renal dysfunction, primarily patients undergoing or approaching dialysis, hence the use of nephrogenic in its name.

Gd-DTPA is a small complex and diffuses easily through the pores of the vessels. Gd-containing contrast agents are rapidly cleared with a half-life of about 2 hours in patients with normal renal function. In chronic renal failure, however, the half-life is prolonged and may exceed 30 - 120 hours. Possible side-effects occur owing to dissociation of the Gd-ligand complex into the metal ion and ligand. The process is facilitated by a combination of endogenous metals (zinc, copper, iron), calcium and endogenous acids, destabilising the complex and leading to its dissociation. In renal failure, the combination of metabolic acidosis and the absence of adequate clearance of Gd-containing agent results in precipitation of salts with anions which are then deposited in the interstitium of muscle, bone, liver and skin.
More than 300 cases of NSF in patients with severe chronic renal insufficiency, acute renal failure or in those undergoing dialysis have been reported in peer-reviewed literature, with an overwhelming majority occurring within weeks to months after injection of a GBCA. ${ }^{[2]}$

\section{Recommendations to prevent NSF}

Because there is no consistently effective treatment for NSF, prevention is important. Screening to identify patients at high risk is essential. ${ }^{[3]}$ Considerable controversy remains about what level of screening is necessary. Because $70-80 \%$ of NSF cases occur in patients undergoing dialysis, screening for dialysis is important. Data on the serum creatinine level should be looked up for all inpatients, and the glomerular filtration rate (GFR) should be calculated to identify patients with a GFR $<30$ $\mathrm{ml} / \mathrm{min}$. The GFR calculation can be done with any of the online calculators. ${ }^{[4]}$

The most up-to-date assessment and guidelines were reported by Thomsen et al. in 2012. ${ }^{[5]}$

\section{Guidelines of the Contrast Media Safety Committee (CMSC) of the European Society of Urogenital Radiology (ESUR) on nephrogenic systemic fibrosis and gadolinium- based contrast media}

Based on the evidence presented in this review, the ESUR CMSC's new guidelines are summarised below, with their strength of evidence and recommendation ratings.

\section{Clinical features}

Onset: From the day of exposure for up to 2 - 3 months, and sometimes up to years, after exposure. Initial syptoms are pain; pruritus; swelling; erythema; usually starting in the legs. 


\begin{tabular}{|c|c|}
\hline \multicolumn{2}{|l|}{ Nephrogenic systemic fibrosis } \\
\hline \multicolumn{2}{|c|}{$\begin{array}{l}\text { A diagnosis of nephrogenic systemic fibrosis (NSF) should only be made if the Yale NSF Registry clinical and histopathological criteria are met } \\
\text { (J Am Acad Dermatol 2011;65:1095-1106). The link between NSF and GBCAs was recognised in } 2006 .\end{array}$} \\
\hline \multicolumn{2}{|l|}{ Patients } \\
\hline At higher risk & $\begin{array}{l}\text { - Patients with CKD } 4 \text { and } 5(\mathrm{GFR}<30 \mathrm{ml} / \mathrm{min}) \\
\text { - Patients on dialysis } \\
\text { - Patients with acute kidney insufficiency }\end{array}$ \\
\hline At lower risk & - Patients with CKD 3 (GFR $30-59 \mathrm{ml} / \mathrm{min}$ ) \\
\hline Not at risk of NSF & - Patients with stable GFR > $60 \mathrm{ml} / \mathrm{min}$ ) \\
\hline Highest risk of NSF & $\begin{array}{l}\text { Gadopentetate dimeglumine (Magnevist plus generic products) } \\
\text { Gadodiamide (Omniscan) } \\
\text { Gadoversetamide (Optimark) }\end{array}$ \\
\hline Recommendations for high-risk group & $\begin{array}{l}\text { These agents are CONTRA-INDICATED in: } \\
\text { - patients with CKD } 4 \text { and } 5 \text { (GFR }<30 \mathrm{ml} / \mathrm{min} \text { ), including those on dialysis } \\
\text { - acute renal insufficiency } \\
\text { - pregnant women } \\
\text { - neonates } \\
\text { These agents should be used with CAUTION in: } \\
\text { - patients with CKD } 3 \text { (GFR } 30-60 \mathrm{ml} / \mathrm{min} \text { ) } \\
\text { - There should be at least } 7 \text { days between } 2 \text { injections. } \\
\text { - children }<1 \text { year old. } \\
\text { Lactating women: Stop breastfeeding for } 24 \mathrm{~h} \text { and discard the milk. } \\
\text { Serum creatinine (eGFR) measurement and clinical assessment of patient before administration is } \\
\text { mandatory. } \\
\text { These agents should never be given in doses }>0.1 \mathrm{mmol} / \mathrm{kg} \text { per examination in any patient. }\end{array}$ \\
\hline
\end{tabular}

Later: Thickened skin and subcutaneous tissues; 'woody' texture and brawny plaques; and fibrosis of internal organs, e.g. muscle, diaphragm, heart, liver, lungs.

Results: Contractures; cachexia; and death, in a proportion of patients. Confounded cases: If two different Gd-CMs have been injected, it is impossible to determine with certainty which agent triggered the development of NSF, and the situation is described as 'confounded'. Unconfounded cases: The patient has never been exposed to more than one agent.
1. Grobner T. Gadolinium - a specific trigger for the development of nephrogenic systemic fibrosis? Nephron Dial Transplant 2006;21:1104-1108.

2. Prince MR, Zhang HL, Prowda JC, Grossman ME, Silvers DN. Gadolinium and neprogenic systemic fibrosis. RadioGraphics 2009;29:1565-1574. [http://dx.doi.org/10.1148/rg.296095517]

3. Kribben A, Witzke O, Hillen U, Barkhausen J, Daul AE, Erbel R. Nephrogenic systemic fibrosis: Pathogenesis, diagnosis and therapy. J Am Coll Cardiol 2009;53(18):1621-1628. [http://dx.doi. org/10.1016/j.jacc.2008.12.061]

4. Fadem SZ. GFR calculator (with SI units): Nephron Information Center Website. http://www.mdrd.com

5. Thomsen HS, Morcos SK, Almén T, et al. Nephrogenic systemic fibrosis and gadolinium-based contrast media: Updated ESUR Contrast Medium Safety Committee guidelines. Eur Radiol 2013;23(2):307-318. [http://dx.doi.org/10.1007/s00330-012-2597-9] 